\title{
Current state of financing health care system in Russia: regional aspect
}

\author{
Olga Nikulina ${ }^{1 *}$ and Alexander Ratkin ${ }^{2}$ \\ ${ }^{1}$ National Research Tomsk State University, Russia, Tomsk, Lenin Ave., 36, 634050, \\ ${ }^{2}$ Siberian State Medical University, Russia, Tomsk, st. Moscow tract, 2, 634050,
}

\begin{abstract}
One of the specific sectors of the economy in Russia is healthcare, which is a complex system of socio-economic relations. An important element of the socio-economic development of the state is precisely the indicators of health and living standards of the population. The relationship between the level of development of the healthcare system and the quality of life of the population is obvious, which ultimately affects the level of national income and the country's economy as a whole. Therefore, in modern conditions of development of our country, the most pressing issue of the health care system is the process of its financing, which is considered in this article in the context of regional characteristics.
\end{abstract}

Keywords: financing, healthcare, compulsory medical insurance, voluntary medical insurance.

\section{Introduction}

In the context of the Russian economy development, the issue of developing the health care system, which is a complex system of socio-economic relations, remains relevant.

The socio-economic development of Russian regions is characterized by significant differences in economic indicators. Depending on the geographic location, macroeconomic changes and crises in the world economy are reflected to varying degrees on the state of the regional economy. The territorial and budgetary imbalances of the country's economy are an important factor. This requires consideration in the design of health financing mechanisms. The presence of economic imbalances should not affect the guarantees of the availability and quality of medical care, regardless of the territory of residence.

The purpose of the article is to identify the main problems of the development of healthcare financing in Russia, analyze and evaluate the effectiveness of existing global systems, and form proposals for the introduction of effective measures for financing the health system.

Methods of descriptive statistics, statistical summaries, graphs, tables, and groupings were used as methodological aspects of the study.

\section{Results}

In Russia in the 2000s, expenditures on health care from all sources of funding, including citizens' funds, differ by region. Under these conditions, when implementing state health policy in terms of health financing, the impact of negative trends in the global economy and expected changes in the regional economy should be taken into account proactively.

Medical care for the population in the Russian Federation is provided on the basis of state guarantees of free medical care, including mandatory medical insurance programs. The

${ }^{*}$ Corresponding author: olganikulyonok@yandex.ru 
implementation of these programs faces significant financial constraints. In some regions, these programs are implemented with a deficit of the required amount of annual funding [1].

Much attention is paid both in foreign and domestic literature to the quality of life of the population and its regional differentiation. However, the goal of the state is not only to ensure a high quality of life for the population, but it is also responsible for the quality characteristics of the population itself [2]. These aspects are impossible without solving the problems of developing the health system in Russia, which closely interacts with the quality of life of the population.

It should be noted that the total expenditure on healthcare in the Russian Federation amounted to $3.2 \%$ of GDP and $9.7 \%$ of total budget expenditures in 2018 . The countries closest to Russia in terms of health expenditure are China $-2.9 \%$ of GDP, Turkey $-3.4 \%$, Latvia $-3.4 \%$, Brazil $-3.9 \%$ and Mexico $-2.9 \%$. Examples of countries with high health spending in 2018 are: Austria-7.6\% of GDP, Germany-9.4\%, Denmark-8.7\%, Sweden-9.1\% and Norway- $8.9 \%$ [3].

Analyzing the current state of Russian healthcare financing, the volume of funding from all sources for medical care of the population from 2013 to 2018 from the consolidated budget of the Russian Federation and the budgets of state extra-budgetary funds increased by 1.43 times and amounted to 3315.9 billion rubles in 2018. In terms of the number of 146.8 million people in 2018, the amount of funding per capita was about 22.6 thousand rubles per year [4].

The largest role in healthcare financing is played by the state with a share of $83 \%$ in 2018 (Fig. 1). This year the population was provided with paid medical services for 677.7 billion rubles, which is $17 \%$ of the total volume of medical services.

Private spending on medicine in 2018 amounted to $17 \%$ and slightly increased in relation to the indicator of $2015-16 \%$. It should be noted that every year the role of the state decreases and the contribution of paid services to the population to the structure of health care financing increases, so in 2013 the state's share was $84.8 \%$, and in $201883.0 \%$. In the 5 -year period under review in 2013-2018, the contribution of the population not only did not decrease, but increased in natural terms from 416.2 billion rubles to 677.7 .

Statistical indicators confirm increased competition in the market of medical services and a decrease in the share of public health. In the period from 2010 to 2018, the total number of hospital organizations in Russia decreased by $15.8 \%$ from 6.3 thousand to 5.3 thousand, and the number of hospital beds for the same period in private organizations increased by 4.2 times from 4.1 thousand to 17 thousand, the number of private outpatient organizations for this period increased by $75 \%$ from 2.8 thousand to 4.9 thousand. Private medical organizations are actively entering the market niches of outpatient and inpatient care, which portends increased competition for the health care system, including for MHI funds [4].

Recently, paid medical services and voluntary medical insurance (VMI) programs bring a certain amount of funds to the Russian healthcare system according to Businessstat in 2018, 15.4 million patients received VMI care, which is $10.3 \%$ of the Russian population. This indicator is relatively stable and in the period $2014-2018$ is in the range of $10.90-10.14 \%$ of the Russian population [5].

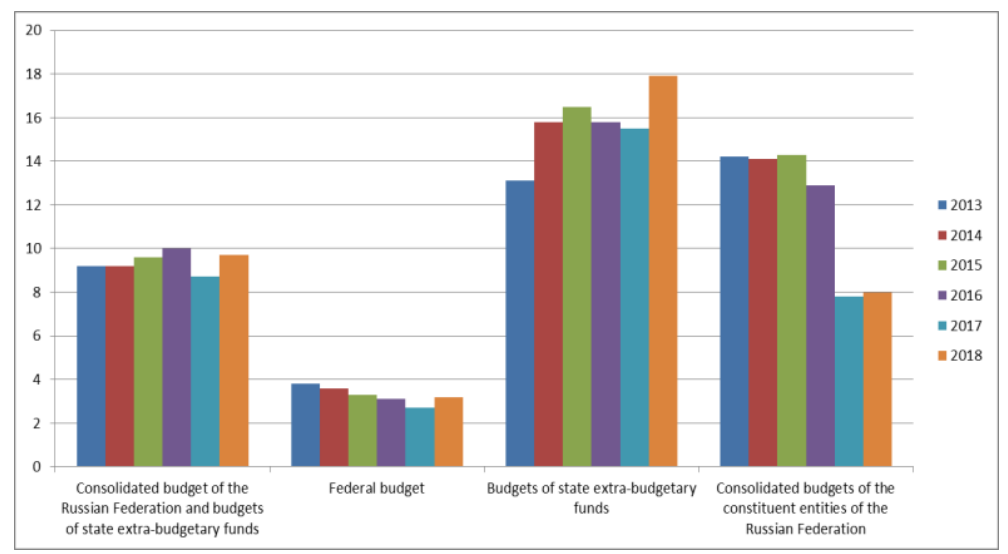

Fig.1. Expenditures of the budget system of the Russian Federation on healthcare in 2013-2018 (as a percentage of total expenditures) [3].

An extremely important indicator is the share of medical services in the total volume of services provided to the population, which is constantly growing. So, in 2010 , it was $5.1 \%$, 
in $2013-6.0 \%$ and in 2018 it reached $7.0 \%$. These changes require additional analysis and sociological research, and may indicate both an increase in the understanding of the importance of health in the population, and a decrease in the ability to spend household funds on other services, while maintaining spending on health.

The current model of financing the healthcare industry, mostly budget-oriented, does not cover all the needs of the population in a guaranteed amount of free medical care. Indicators of the health system may differ significantly from region to region, for example, in 2017, the population per doctor in the regions differed by almost 2.9 times and ranged from 124.0 to 357.4 people [6]. The number of cardiac beds per 10,000 population differed almost 3.2 times and was in the range of $1.7-5.4$ [7].

It is obvious that the trend towards an increase in expenses for paid medical services continues, since the concept of the development of a welfare state will necessitate not only preserving, but also expanding the list of social guarantees in health care.

The existing financing mechanism in healthcare based on the priority of the system of compulsory medical insurance as payment for medical care is undergoing a serious strain and ceases to be effective. In this regard, there is a need to create new effective sources of financing for medical services, as well as a mechanism for its operation, taking into account regional characteristics.

It is impossible to agree with the opinion of O. A. Khokhlova and A. B. Shatonov that improving the efficiency of the Russian health care system should be based on the rationalization of its financing processes, primarily by creating conditions for the redistribution of public funds from the sector of paid medical services to the sphere of voluntary medical insurance. Effective implementation of this measure determines the need for a statistically based selection of specific reference countries, whose experience in the development of voluntary health insurance (VHI) can be applied in Russian conditions [1].

Since the introduction of the VHI in the Russian insurance market until about 2004, there has been a relatively high growth rate in the number of contracts concluded annually. Since 2004 , the growth in the number of contracts has slowed markedly. In 2006-2016, the number of contracts fluctuated between 9-11.4 million per year. The agreements covered $6-8 \%$ of the Russian population. The main part of the VHI market is accounted for by corporate clients due to the optimality of this type of insurance for insurers; in addition, the employee VHI allows companies to receive tax benefits. As a result, for example, in Moscow and Saint Petersburg, according to experts, VHI is $95 \%$ corporate insurance. In the regions, companies insure their employees less often and, if they do, prefer Deposit insurance and the use of VHI to Finance their own medical unit or organize treatment of employees in sanatoriums and dispensaries [8].

The conducted statistical research by O. A. Khokhlova and A. B. Shatonov showed that insurance systems of healthcare financing are recognized as the most progressive and socially significant in the world, since they allow ensuring high availability of free medical care to the General population at a qualitative level. However, the main problem of such systems is their high cost and the ever-growing deficit in the fulfillment of obligations under state guarantees. In these conditions, sooner or later, there will be a need to develop alternative sources of state funding for medical care. Therefore, the creation of conditions for the development of voluntary medical insurance should become a new stage in the reform of the national health system [1].

The data analysis conducted by E. I. Kozyrenko and L. O. Avdeeva showed that currently the underfunding of territorial programs is compensated by the population independently by applying to the sphere of voluntary medical insurance and paid medical services. It is noted that the main goal of further transformation of the VHI system should be to increase the amount of funding for the system. When adjusting state obligations, it is necessary to take into account the presence of a deficit of financial support for territorial programs of state guarantees, which has already been reallocated due to its lack of security, but without legislative consolidation. The redistribution reserve will be an increase in payments under VHI contracts and funds received by medical organizations from the provision of paid medical services [9].

If the spending policy of the Russian budget is reduced, the prospects for financial provision of health care will be even more strongly linked to the capabilities of regional budgets and the Federal budget service. Further development of the obligatory medical insurance system should be based on ensuring sustainable financing of medical institutions, so that the population can get guaranteed medical care as necessary; it can be achieved by attracting additional sources of funding. If the retirement age increases, the amount of contributions not only to the Pension Fund of the Russian Federation, but also to the mandatory medical insurance Fund will increase at the expense of the working population. 
Thus, the amount of healthcare funding will increase. In addition, it is necessary to achieve a balance between payments made to the Federal compulsory health insurance Fund by employers and the obligations of Executive bodies of state power engaged in insurance of the non-working population [9].

We agree with the authors' opinion that when adjusting state obligations, it is necessary to take into account the existence of a deficit of financial support for territorial programs of state guarantees, which has already been reallocated due to its lack of security, but without legislative consolidation. The reallocation reserve will be an increase in payments under voluntary medical insurance contracts and funds received by medical organizations from the provision of paid medical services. At the same time, special attention should be paid to the potential growth of the market for voluntary medical insurance and paid medical services. This will determine the increase in the amount of financial obligations that can be redistributed in the healthcare sector of the Russian Federation [9]. Indeed, after analyzing the financing of health care in the regional aspect, we can conclude that there are cases of inefficient redistribution of finances. Many authors pay attention to these facts, Including F. N. Kadyrov, O. V. Obukhova, A. S. Brutova, pointing out the paradoxes of health care financing in terms of excessively discovered funds in the system of mandatory medical insurance, sent to the Federal budget of the country.

According to some researchers [10] the basic problem of financing health care at present is that the budget of the Federal compulsory medical insurance Fund burden serious expenditure commitments for financial support of high-tech medical care, financial support of the Federal clinics, as well as expenses not directly related to health care.

There is a slightly different approach to financing in European countries, where joint insurance of non-working family members is often used to pay for medical care for pensioners, children, the disabled and the unemployed. This experience in the future, as the development of mandatory medical insurance and the strengthening of the insurance principle of financing medical care could be applied in domestic practice. In Russia, insurance for children, students, disabled people and pensioners is mainly provided by the state budget. In contrast to countries with health insurance systems, where the principle of parity in reimbursement of medical care costs is observed, it is absent in Russian practice. The funds collected by the mandatory medical insurance funds are spent on financing territorial mandatory medical insurance programs, which are part of the state guarantee programs to provide citizens with free medical care. The minimum package of medical services of the basic compulsory medical insurance program, funded by these funds, includes a limited amount of medical care in comparison with a broader list of services under the mandatory medical insurance programs in the EU countries [11].

\section{Conclusions}

In the context of the challenges facing the country and the implementation of national projects, it is urgent to find ways to modernize the conditions for financing the health care system in Russia. Special attention should be paid to the regional aspect when developing proposals, since the subjects of the Russian Federation are extremely heterogeneous in terms of socio-economic development.

Throughout its history, the system of compulsory medical insurance has contributed to the development of healthcare financing, improved the quality of services provided, and stimulated the introduction of market principles in the interaction of medical organizations and financing tools. However, we propose certain measures as potential areas for changing the compulsory health insurance system towards its efficiency. First, it is necessary to align the regions and the living population in relation to the amount of aid, which is a socially fair decision. Secondly, it is necessary to centralize the management of financial flows. Thirdly, it is necessary to increase the transparency of the system and the conditions for access of market participants of medical activities to the means of compulsory medical insurance. Fourthly, the "digitalization" of the industry is extremely important - the introduction of information technologies and, possibly, in the future, artificial intelligence in the management of financial flows and the volume of assistance provided. In addition, it is imperative to introduce the experience of European countries in voluntary health insurance programs.

Special attention should be paid to the factors of macroeconomic instability, the coronavirus pandemic and the continuing imbalance of regions in terms of income, which has a direct impact on the volume of mandatory health insurance funds and the structure of regional budgets. These factors should be considered as risks that need to be carefully focused 
on when modernizing the health financing environment. Taking into account the component of the mandatory health insurance Fund, which consists of employers' funds based on deductions from the labor remuneration Fund, by the end of 2020, we can predict a decrease in this indicator due to the suspension of the activities of most enterprises in our country.

\section{References}

1. O.A. Khokhlova, A.B. Shatonov, Economic and statistical study of the effectiveness of the Russian health system in a comparative international aspect, Economic analysis: theory and practice, 9, 4-15 (2016)

2. V.V. Lokosov, E.V. Ryumina, V.V. Ulyanov, Population Quality and regional economy: direct and reverse links, Economic and Social Changes: Facts, Trends, Forecast, 11(1), 32-42 (2018)

3. Healthcare in Russia. 2019: a Statistical compendium (Rosstat, Moscow, 2019)

4. The Number of permanent population on January 1, 2019, https://showdata.gks.ru/report/278928/ (accessed: 02.07.2020).

5. Analysis of the voluntary medical insurance market in Russia in 2014-2018, forecast for 2019-2023, https://businesstat.ru/images/demo/voluntary_health_insurance_russia_2019_demo_bu sinesstat.pdf (accessed: 02.07.2020).

6. Federal state statistics service. Population per doctor in 2017 https://showdata.gks.ru/finder/descriptors/297852 (accessed: 02.07.2020).

7. Federal state statistics service. Provision of hospital beds per 10,000 population (at the end of 2017, https://showdata.gks.ru/finder/descriptors/297752 (accessed: 02.07.2020).

8. A. Aistov, E. Alexandrova, Post-contract opportunism in the market of voluntary medical insurance, Economic policy, 13(3), 148-181 (2018) DOI: 10.18288/19945124-2018-3-07.

9. E.I. Kozyrenko, L.O. Avdeeva, Current state of healthcare financing in Russia, Vestnik AGTU, 1, 153-164 (2019) DOI: 10.24143/2073-5537-2019-1-153-164.

10. F.N. Kadyrov, O.V. Obukhova, A.S. Brutova, Paradoxes of healthcare financing in 2016: extra funds were found in the MHI system that will be withdrawn to the Federal budget, Health manager, 1, 56-67 (2016)

11. V.V. Antropov, Financing of healthcare: European experience and Russian practice, Economy. Tax. Pravo. 2, 115-126 (2019) 